Article

\title{
Evaluation of Somaclonal and Ethyl Methane Sulfonate-Induced Genetic Variation of Mexican Oregano (Lippia graveolens H.B.K.)
}

\author{
Luis A. Muñoz-Miranda ${ }^{1}$, Araceli Rodríguez-Sahagún ${ }^{1}{ }^{\circledR}$, Gustavo J. Acevedo Hernández ${ }^{1}($, \\ Victor O. Cruz-Martínez ${ }^{1}$, Martha I. Torres-Morán ${ }^{2}$, Rogelio Lépiz-Ildefonso ${ }^{2}$, \\ Rayn C. Aarland ${ }^{1}$ and Osvaldo A. Castellanos-Hernández ${ }^{1, * \mathbb{D}}$ \\ 1 Laboratorio de Biología Molecular Vegetal, Centro Universitario de la Ciénega, Universidad de Guadalajara, \\ Ave. Universidad 1115, Col. Lindavista, 47820 Ocotlán, Mexico; \\ luis.mmiranda@academicos.udg.mx (L.A.M.-M.); aracelicrs@gmail.com (A.R.-S.); \\ gacevedo72@gmail.com (G.J.A.H.); cruzobet@gmail.com (V.O.C.-M.); rayn.aarland@cuci.udg.mx (R.C.A.) \\ 2 Centro Universitario de Ciencias Biológicas y Agropecuarias, Universidad de Guadalajara, \\ km 15.5 carretera a Nogales, 45101 Zapopan, Mexico; isabel.torres@academicos.udg.mx (M.I.T.-M.); \\ rlepiz@cucba.udg.mx (R.L.-I.) \\ * Correspondence: ocnoscr@gmail.com; Tel.: +392-9259-400
}

Received: 7 March 2019; Accepted: 25 March 2019; Published: 29 March 2019

\begin{abstract}
Lippia graveolens, commonly known as Mexican oregano, is an aromatic plant of great industrial, nutritional, and medicinal value, principally for its essential oils. Regeneration via axillary buds was established in MS medium supplemented with 6-benzyladenine (BA) $\left(0.5 \mathrm{mgL}^{-1}\right)$ as a growth regulator. Three genotypes and three stages of cultivation were considered in the study. On average, 3.5, 4.2, and 6.4 shoots induced per explant were obtained for genotypes B, C, and $\mathrm{D}$, respectively. Several doses $(0.1,0.3$, and $0.5 \%)$ of ethyl methane sulfonate (EMS) and different exposure times $(1,2$, and $3 \mathrm{~h})$ were applied to investigate the effect of the chemical mutagen on the formation of axillary buds. Genetic variation among the collected plants, the micro-propagated plants during three sub-cultivations, and the plants regenerated in the presence of the mutagen was evaluated by means of randomly amplified microsatellite polymorphism (RAMP) markers. A high genetic stability was observed in the micro-propagation of Mexican oregano for the three genotypes and three sub-cultivations, presenting $100 \%$ of monomorphic bands. The genetic variation observed in the different collections of wild populations (A, R, and V) and after treatment with EMS regarded 34 and $35 \%$ of polymorphic loci, respectively.
\end{abstract}

Keywords: Lippia graveolens; EMS; micropropagation; RAMP

\section{Introduction}

Under the name of oregano, there are several known species of herbaceous plants belonging to two families: Lamiaceae and Verbenaceae [1]. In Mexico, there are around 40 species of oregano belonging to four families (Lamiaceae, Verbenaceae, Asteraceae, and Leguminosae), of which the Verbenaceae family is the most commercially important because of its aromatic characteristics and its distribution [2]. The species Lippia palmeri Watson, Lippia berlandiefi Schauer, and Lippia graveolens H.B.K belong to this family. The latter two species are recognized as synonymous by many authors [1-3].

L. graveolens, commonly known as Mexican oregano, is an herbaceous plant with great commercial potential due to its culinary and medicinal uses. It is a species native to the southern United States of America, Mexico, and part of Central America [4]. It is an aromatic species whose essential oil is composed primarily of two monoterpenes, thymol and carvacrol, to which various properties 
and uses have been attributed [5]. The essential oil is used in the soft drink, liquor, cosmetics, and pharmaceutical industry $[1,6]$, in the manufacturing of soaps, perfumes, and aromatherapy products, and as an antimicrobial $[7,8]$ and antioxidant $[9,10]$ product.

The propagation of $L$. graveolens naturally occurs through the union of gametes for the formation of seeds (embryo). It has been reported that only $11 \%$ of the flowers produce fruit, and each fruit usually contains only one seed. If we add to this the inadequate implementation of agronomic management practices, which alters the normal development of the fruits and seeds, and the low percentage of germination that they present, the result is a critical reduction in the size and density of its populations $[11,12]$.

The application of tissue culture techniques has allowed the massive propagation of plants under aseptic and regulated conditions [13]. The regeneration of Mexican oregano has been developed through the in vitro establishment of leaves, with callus formation, and through axillary bud multiplication [14].

Tissue culture tools have also permitted the improvement of species with the purpose of generating plants with better agronomic or aromatic characteristics. In addition to this, in vitro cultivation has also been utilized for the induction of mutations through the use of physical or chemical agents, generating plants with characteristics different from those of their parents [15-17].

The use of molecular markers allows to evaluate the genetic changes that occur naturally in wild populations, those generated by in vitro cultivation, and those induced by the use of mutagens. The development of PCR-based markers, which include the random amplified polymorphic DNA (RAPD), simple sequence repeat (SSR), inter simple sequence repeat (ISSR), randomly amplified microsatellite polymorphism (RAMP), among others, has been useful to determine the genetic variability in plants under these conditions $[18,19]$.

The objective of the present work was the in vitro establishment and propagation of Mexican oregano, the induction of genetic changes through the use of the chemical mutagen ethyl methane sulfonate (EMS), and the evaluation of the genetic variability using RAMP markers, in order to develop plants with superior agronomic characteristics.

\section{Materials and Methods}

\subsection{Plant Material}

L. graveolens seeds were collected from wild plants in the municipality of Colotlán, located in the North of the state of Jalisco, Mexico.

\section{Conditions for In Vitro Germination of Mexican Oregano}

The oregano seeds used for the study were selected from three collections (A, R, and V). The seeds were germinated in vitro in MS medium (Murashige and Skoog) [20] with $50 \%$ of the original salt concentration, $1 \%$ sucrose, $0.25 \%$ phytagel (Sigma P8169), and the $\mathrm{pH}$ was adjusted to $5.8 \pm 0.2$ before sterilization in an autoclave at $121^{\circ} \mathrm{C}$ for $15 \mathrm{~min}$.

For the disinfection of the seeds, $70 \%$ ethanol was used for one minute and $40 \%$ commercial bleach for six minutes, followed by three washes with sterile water for $1.5 \mathrm{~min}$. The seeds established in the MS medium were incubated at $25^{\circ} \mathrm{C}$ with a photoperiod of $16 / 8 \mathrm{~h} \mathrm{light/dark} \mathrm{under} \mathrm{fluorescent}$ white light lamps with an intensity of $32 \mu \mathrm{mol} \mathrm{m}^{-2} \mathrm{~s}^{-1}$.

\subsection{Micropropagation of Mexican Oregano}

The micropropagation of Mexican oregano from axillary buds was carried out according to what was reported by Castellanos-Hernández et. al. [14]. The nodal segments were obtained from three plants germinated in vitro, designated B, C, and D (mother plants), which were derived from collection A. The segments were grown in MS medium supplemented with $0.5 \mathrm{mg} \mathrm{L}^{-1}$ of benzyladenine (BA), $3 \%$ sucrose, and $0.25 \%$ phytagel for solidification. The $\mathrm{pH}$ of the medium was adjusted to $5.8 \pm 0.2$. 
The nodal segments were incubated at $25{ }^{\circ} \mathrm{C}$ with a photoperiod of $16 / 8 \mathrm{~h}$ light/dark under fluorescent white light lamps with an intensity of $32 \mu \mathrm{mol} \mathrm{m}{ }^{-2} \mathrm{~s}^{-1}$. Three sub-cultivations of the mother plants B, C, and D were carried out (12 replicates, mother plant/sub-cultivation).

\subsection{Chemical Mutagenesis in Axillary Buds of L. graveolens}

Mutagenesis in axillary buds was carried out in plants belonging to genotype D (at the first sub-cultivation from the mother plant). The nodal segments were devoid of leaves and contained one or two nodes, which were submerged in $0.1 \%, 0.3 \%$, and $0.5 \%$ EMS mutagen solution with exposure times of 1,2 , and $3 \mathrm{~h}$. After the treatments, the explants were washed five times in sterile water under aseptic conditions to eliminate the remaining EMS. The washed explants were established in the medium for propagation and under the same conditions of incubation, described in the previous section. The treatments were performed with 10 replicates. Data were analyzed using analysis of variance (ANOVA) with two factors (mutagen concentration and exposure time). When the ANOVA identified differences among groups, multiple comparisons among means were performed using Tukey's multiple range test with a family error rate of 0.05 . The software package Statgraphics (Statistical Graphics Co.) was used for the analysis. Different letters were used to designate groups with significant difference at $p<0.05$.

\subsection{Analysis of the Genetic Variability Using RAMP Markers}

The extraction of genomic DNA was performed according to the protocol described by Zhang and Hewitt [21], with minor modifications. The quality of the extracted DNA was analyzed in $1 \%$ agarose stained with ethidium bromide. DNA quantification was performed by UV spectrophotometry using a NanoDrop 2000 spectrophotometer (Thermo Scientific ${ }^{\circledR}$, Wilmington, DE, USA). Values of the samples in the absorbance ratio $260 / 280$ between 1.8 to 2.0 were taken as indicating good-quality DNA.

For the RAMP analysis, five plants, selected from each micro-propagation sub-cultivation, and the mother plant were used (a total of 16 plants per genotype); 20 plants were obtained from seeds germinated in vitro from three different collections; 20 plants were obtained after the mutagenic treatment ( $0.1 \%$ EMS, $2 \mathrm{~h}$ exposure). Three ISSR primers were used, which were ARS-01 (5'-CACT(GA)6-3'), ARS-02 (5'-AACC(GA)6-3'), and ARS-08 (5'-TCGG(GA)6-3'), and three RAPD primers, which were OPB-07 (5'-GGTGACGCAG-3'), OPB-08 (5'-GTCCACACGG-3'), and OPB-12 (5'-CCTTGACGCA-3'). Nine combinations were used for the RAMP (Table 1). The amplification reactions were performed in a final volume of $12.5 \mu \mathrm{L}$ containing $5 \mathrm{ng}$ of genomic DNA, 1X PCR buffer, $2.0 \mathrm{mM} \mathrm{MgCI}_{2}, 0.25 \mu \mathrm{M}$ of each dNTP, $0.3 \mu \mathrm{M}$ of each primer, and $0.5 \mathrm{U}$ of DNA polymerase (Promega). The amplifications were performed in a TC-412 thermal cycler (Techne ${ }^{\circledR}$, Staffor, TX, USA) using the program: $94{ }^{\circ} \mathrm{C}$ for one min, 45 cycles of one min at $94{ }^{\circ} \mathrm{C}$, one min at $36^{\circ} \mathrm{C}$, two min at $72{ }^{\circ} \mathrm{C}$, and a final extension of $10 \mathrm{~min}$ at $72{ }^{\circ} \mathrm{C}$. The amplification products were analyzed by electrophoresis in $2 \%$ agarose [22] stained with ethidium bromide $\left(1 \mathrm{mg} \mathrm{L}^{-1}\right)$ and visualized in a UV light transilluminator. The $100 \mathrm{bp}$ Plus ladder (Invitrogen) was used as a molecular weight marker.

Table 1. Combinations of inter simple sequence repeat (ISSR) and random amplified polymorphic DNA (RAPD) primers for the randomly amplified microsatellite polymorphism (RAMP) Technique.

\begin{tabular}{ccc}
\hline Primer RAPD & Primer ISSR & Combination \\
\hline OPB-07 & ARS-01 & 1 \\
OPB-08 & ARS-01 & 2 \\
OPB-12 & ARS-01 & 3 \\
OPB-07 & ARS-02 & 4 \\
OPB-08 & ARS-02 & 5 \\
OPB-12 & ARS-02 & 6 \\
OPB-07 & ARS-08 & 7 \\
OPB-08 & ARS-08 & 8 \\
OPB-12 & ARS-08 & 9 \\
\hline
\end{tabular}




\subsection{Data Analysis}

The detected polymorphisms were indicated by the presence (1) or absence (0) of a band in the agarose gel. With these data, binary matrices were prepared, which were used to calculate values of genetic similarity between each genotype using the Jaccard coefficient, included in the statistical package NTSYS-pc version 2.00 (Applied Biostatistics Inc., Setauket, NY, USA). Dendrograms were prepared by applying the algorithm UPGMA (Unweighted Pair-Group Method with Arithmetical Averages) [23] through the PAST program [24]. Dendrograms of genetic similarity (GS) values were obtained considering samples of oregano obtained from seeds, propagated in vitro, and exposed to EMS.

\section{Results}

\subsection{In Vitro Propagation}

The cultivation of nodal explants in MS medium supplemented with $0.5 \mathrm{mg} \mathrm{L}^{-1}$ of BA resulted in averages of 3.5, 4.2, and 6.4 shoots per explant of the genotypes named B, C, and D, respectively (Figure 1).

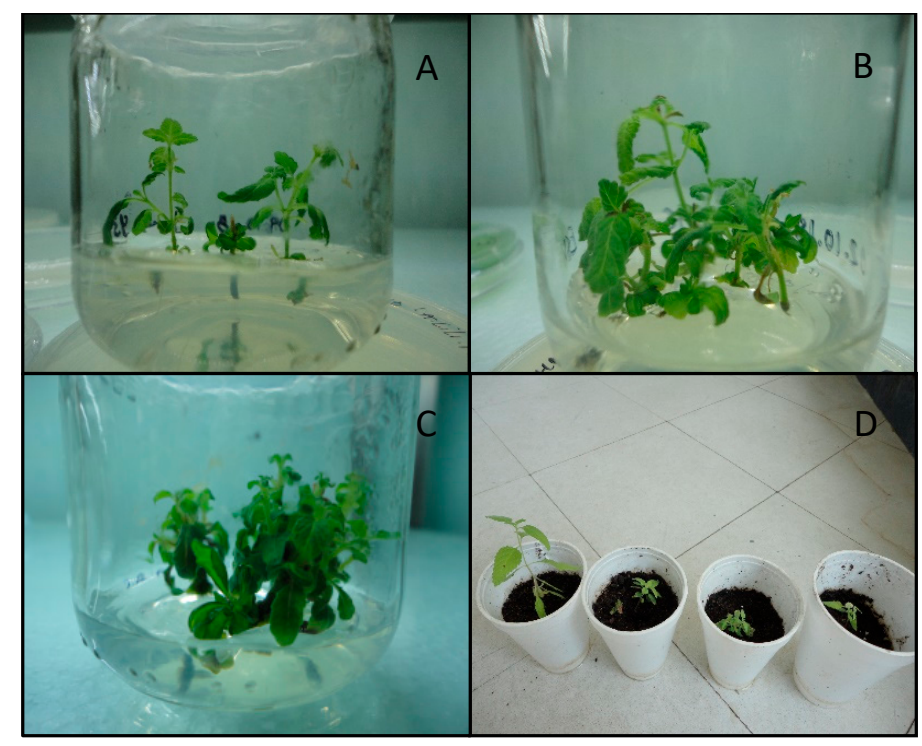

Figure 1. Production of shoots from axillary buds of Mexican oregano (genotype D) in MS medium, from the first sub-cultivation (A), second sub-cultivation (B), and third sub-cultivation (C); oregano established in soil under greenhouse conditions (D).

The average number of shoots obtained from axillary buds by adding BA to the medium, was higher than that reported by Castellanos-Hernández et al. [14], who describe an average of 2.8 shoots per explant, using the same conditions. In addition, that report only showed activation of buds, in comparison with the results presented here. This may be due to the genotype of the plant, as it may respond differently to the same cultivation conditions [25].

The use of cytokinins, such as BA, in the proliferation of axillary buds by nodal segments has been reported in several propagation studies [13,14,25]. Islam et al. [26] report the use of BA at a concentration of $0.05 \mathrm{mg} \mathrm{L}^{-1}$ in the in vitro propagation of Vitex negundo L., showing production of multiple shoots.

The number of shoots generated in each stage of micro-propagation of the three genotypes did not present significant changes, although the length of the shoots decreased in successive propagations. The number of shoots can be increased in each number of sub-cultivations or kept constant. The increase in the number of plants is compensated by the increase of sub-cultivations $[27,28]$. 
This method of in vitro propagation by axillary buds represents an alternative route for the multiplication of Mexican oregano for which the natural reproduction routes are limited. Therefore, it represents a highly efficient propagation system to be implemented in commercial crops.

\subsection{Mutagenesis}

EMS-treated plants showed a decrease in the regeneration rate as the concentration and exposure times increased. The concentration of $0.1 \%$ EMS and the exposure times of 1 and $2 \mathrm{~h}$ presented the best results in terms of shoot production and length $(p<0.05)$ (Table 2). The formation of shoots upon the different mutagenesis treatments was affected by the time and the concentration of the mutagenic agent, resulting in a lower number of shoots in all treatments compared with the control without mutagenic treatment. However, it was observed that all shoots obtained from the treated explants showed similar shoot length. Higher concentrations and exposure times of $3 \mathrm{~h}$ were found to be toxic to the plants (Figure 2).

Table 2. Number of shoots per explant after the different treatments with EMS.

\begin{tabular}{cccc}
\hline $\begin{array}{c}\text { EMS } \\
\text { Concentration (\%) }\end{array}$ & $\begin{array}{c}\text { Exposure Time } \\
\text { (h) }\end{array}$ & $\begin{array}{c}\text { No. of Shoots } \\
\text { per Explant }\end{array}$ & $\begin{array}{c}\text { Length of the } \\
\text { Shoots (cm) }\end{array}$ \\
\hline 0.1 & 1 & $2.9 \pm 0.3 \mathrm{a}$ & $2.1 \pm 0.2 \mathrm{x}$ \\
0.1 & 2 & $2.0 \pm 0.4 \mathrm{a}$ & $2.0 \pm 0.1 \mathrm{x}$ \\
0.1 & 3 & $1.2 \pm 0.1 \mathrm{~b}$ & $0.8 \pm 0.1 \mathrm{y}$ \\
0.3 & 1 & $1.5 \pm 0.4 \mathrm{~b}$ & $1.9 \pm 0.4 \mathrm{x}$ \\
0.3 & 2 & $1.0 \pm 0.0 \mathrm{~b}$ & $1.6 \pm 0.3 \mathrm{x}$ \\
0.3 & 3 & $0.0 \pm 0.0 \mathrm{c}$ & $0.0 \pm 0.0 \mathrm{z}$ \\
0.5 & 1 & $1.3 \pm 0.1 \mathrm{~b}$ & $1.7 \pm 0.1 \mathrm{x}$ \\
0.5 & 2 & $0.2 \pm 0.1 \mathrm{c}$ & $0.9 \pm 0.2 \mathrm{y}$ \\
0.5 & 3 & $0.0 \pm 0.0 \mathrm{c}$ & $0.0 \pm 0.0 \mathrm{z}$ \\
\hline
\end{tabular}

The letters represent homogeneous groups; different letters indicate significant difference $(p<0.05) ;{ }^{*}$ represents the mean of 10 replicates \pm standard deviation.

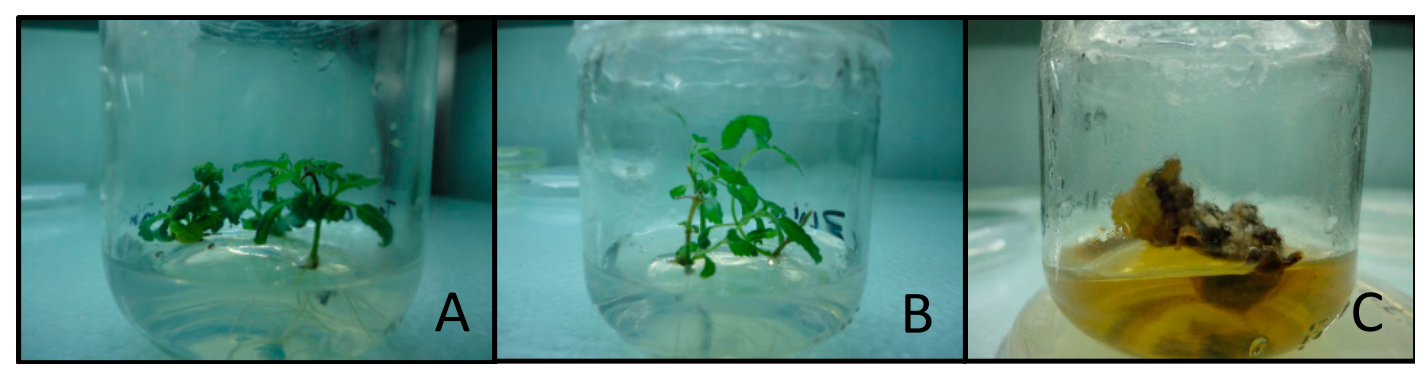

Figure 2. Lippia graveolens explants at different exposure times of mutagenesis treatment $(0.3 \%$ ethyl methane sulfonate (EMS)): 1 (A), 2 (B) and 3 (C) h.

Junaid et al. [29] reported a similar behavior. The reduction in adventitious bud induction frequency, as well as in the size of the shoots, was observed in the in vitro cultivation of Dracaena sanderiana Sander ex Mast with the increase of EMS. Increased concentration of EMS can generate lesions and can be lethal for the explant [30].

Regarding the phenotype of the explants obtained, no changes were observed in the morphology of the plant. Mutations do not always show obvious changes in morphology or growth rate [29,31]. One way of demonstrating the changes generated in the explant by mutagens is through the use of molecular markers [32,33].

\subsection{RAMP Analysis}

The RAMP band patterns obtained from the three genotypes (B, C, and D) and from the three stages of in vitro propagation were compared with those of the donor mother plant. Nine combinations 
of RAPD and ISSR primers produced different amplification profiles, but the same banding pattern was seen in all plants propagated in vitro when compared with the mother plant, showing a high degree of homogeneity in the population of Mexican oregano micro-propagated by axillary buds.

The banding profile of the micro-propagated plants was monomorphic and identical to that of the mother plant (Figure 3b). The samples were compared with DNA from Paulownia elongata and Sechium edule plants obtained by tissue culture used as outliers in the banding profile. The similarity matrix based on the Jaccard coefficient revealed a value of 1 between the mother plant and those derived from the three sub-cultivations, indicating $100 \%$ similarity. A total of 115,70 , and 54 bands were detected in genotypes $B, C$, and D, with an average of $12.7,7.7$, and 6 bands per primer, respectively. The amplified fragments generated by RAMP ranged from 2 (combination 1, genotype D) to 20 (combination 6, genotype B), with a size range from 200 to $1650 \mathrm{bp}$.

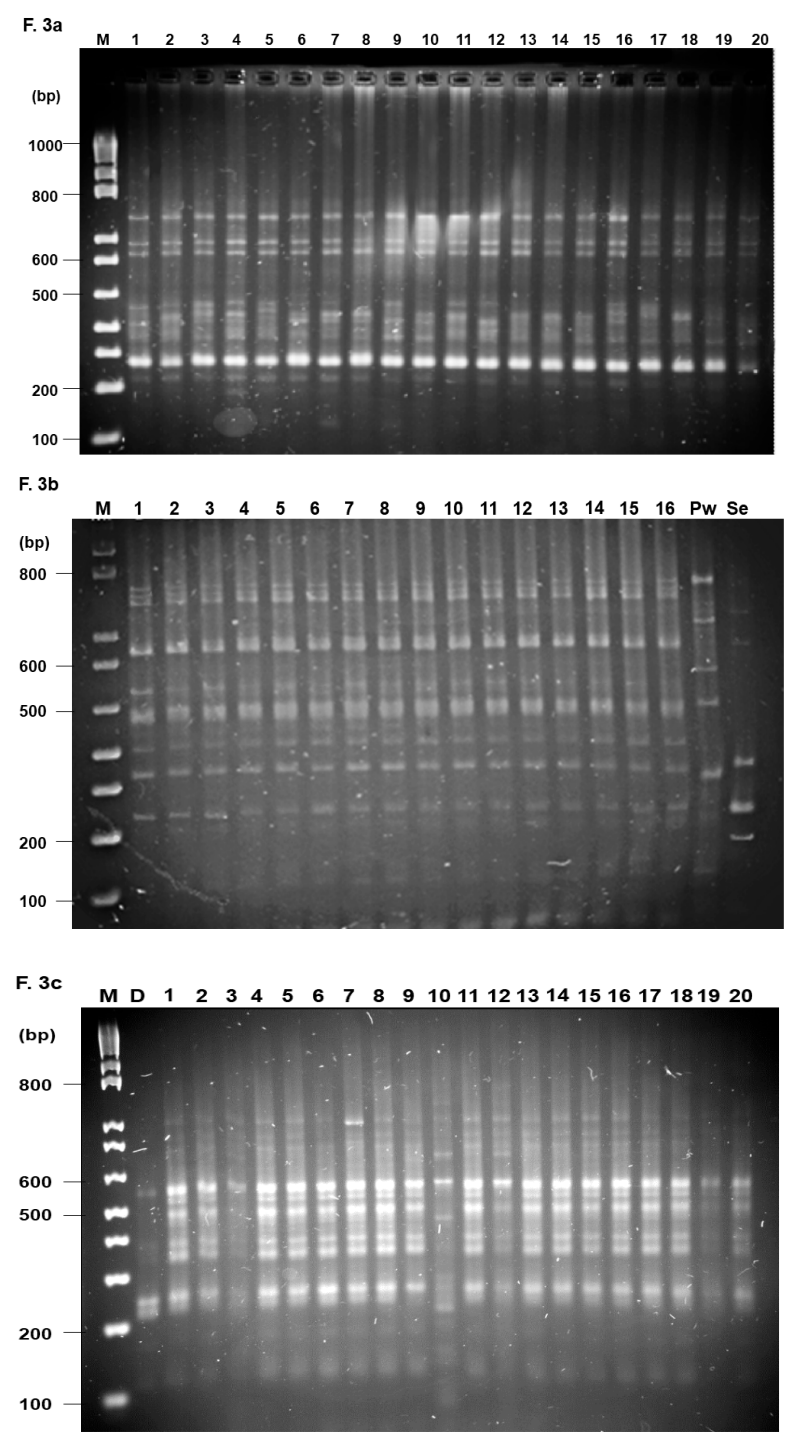

Figure 3. RAMP polymorphism of L. graveolens after different in vitro treatments. (a) Agarose gel electrophoresis for primer combination 5 (OPB-08 and ARS-02). Plants obtained from 20 seeds of L. graveolens, collection A (lines 1-9), collection R (lines 10-13), collection V (lines 14-20). (b) Agarose gel electrophoresis for primer combination 2 (OPB-12 and ARS-08). Plants obtained from genotype B (mother plant, lane 1), lane 2-6 first subcultivation, lane 7-11 second subcultivation, lane 12-16 third subcultivation, Se: Sechium edule and Pw: Paulownia elongata as a control. (c) Agarose gel electrophoresis for primer combination 5 (OPB-07 and ARS-02). Lane 1-20 plants obtained after the mutagenic treatment $(0.1 \%$ EMS, $2 \mathrm{~h}$ exposure), D: control plant. 
The evaluation of the genetic fidelity of the micro-propagated plants through molecular markers has been reported in several papers [34-36]. The evaluation of genetic stability in L. graveolens was performed in the first three sub-cultivations. Rathore et al. [36] demonstrated genetic stability during micropropagation via nodal segments of Jatropha curcas L. by means of RAPD, ISSR, and SSR markers at 5,10 , and 20 stages of sub-cultivation. This confirms that micropropagation by axillary bud maintains the quality of the plants for commercial use.

In regard to the plants obtained from seeds, the RAMP analysis showed a percentage of polymorphism of $34 \%$, with 32 polymorphic bands. The amplified fragments generated by each primer combination had a size range between 200 and $1650 \mathrm{bp}$ (Figure 3a). The nine combinations of primers evaluated showed reproducible bands with a total yield of 95 bands and an average of 10.5 bands per primer. The number of bands for each primer varied between 5 (combination 8 ) and 17 (combination 4).

The genetic relationship observed in the dendrogram based on the existing similarity from the banding profile of the RAMP markers using the nine combinations of primers (Figure 4) showed an inhomogeneous grouping of the three different collections $(A, R, V)$. The majority of individuals obtained from collection A grouped in cluster 1 (A6, A9, and A7) and 2 (A2, A3, A4, and A1), as well as some samples from collections R (R2, R3, and R4), with a coefficient of similarity of 0.92 . The samples of collection $\mathrm{V}$ were more dispersed in the cluster (V7, V6, V1, and V5), with a coefficient lower than 0.90, although some samples (V2, V3, and V4) grouped together with the collections A and R.

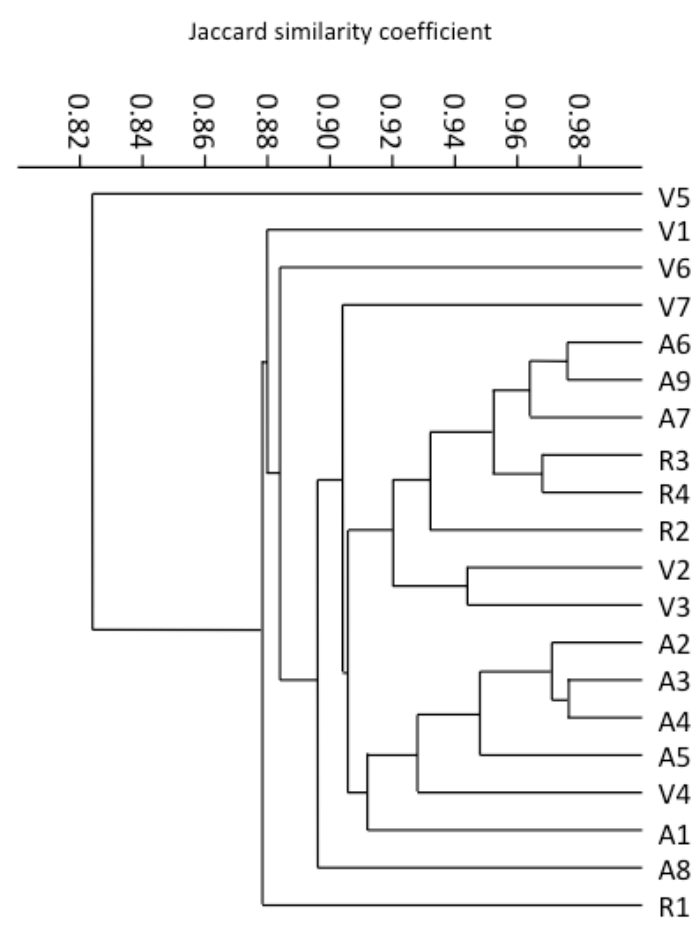

Figure 4. Dendrogram obtained with RAMP markers, using the nine combinations of primers, for the plants obtained by in vitro germination of the three collections A (A1-A9), R (R1-R4), and V (V1-V7).

This grouping of the three collections gathered in the North of the state of Jalisco suggests that the level of genetic diversity found in this species could indicate a considerable influence of cross-breeding in the reproduction of L. graveolens, which is a species with the capacity of cross-pollination or self-pollination [12]. We could observe this behavior in the grouping and genetic similarity of the different individuals.

RAMP markers have been used in several plant species to determine genetic diversity and have been shown to be highly polymorphic [22,32,37]. Zhao et al. [37] presented a banding pattern between 250 and $1000 \mathrm{bp}$ with an average of 8.75 bands per primer using RAMP markers in different 
pomegranate genotypes, with a percentage of polymorphism of $88.90 \%$. The individuals were not grouped according to their geographical origin, which strengthens the argument that the result was due to the reproductive characteristics of the species.

Regarding the 20 plants treated with EMS, chosen at random since they did not present changes in morphology, the analysis of RAMP markers showed polymorphic bands in seven of the nine combinations, with a total of 34 bands, which represents a polymorphism of $35 \%$. The amplified fragments generated by each primer were between 200 and $1000 \mathrm{bp}$, with an average yield of 10.8 bands per primer (Figure 3c). In the RAMP profiles, new bands or the absence of bands were observed between the mutants and the control.

It is noteworthy that the EMS treatment allowed to obtain a group of plants with a percentage of polymorphism similar to that observed in plants established from wild collected seeds, even though the in vitro propagation protocol itself produced only plants with no detectable polymorphism using RAMP markers. Hence, this EMS-induced mutagenesis appears to be a convenient alternative to increase the genetic diversity in the short term and to obtain new genotypes with desirable agronomic traits. It would be particularly interesting to evaluate changes in features such as biomass accumulation and the yield and composition of the essential oil.

The dendrogram displays the individuals treated with EMS, which showed a coefficient of GS of 0.82 and 1.00. Samples 1M and 19M presented a low level of similarity in comparison with the rest of the samples (GS between 0.92 and 1.00). This relationship was established between the same plants treated with the mutagen compared to the control without mutagenesis treatment (D). This showed variations at the DNA level in the plants treated with the EMS mutagen, evaluated by means of RAMP markers (Figure 5).

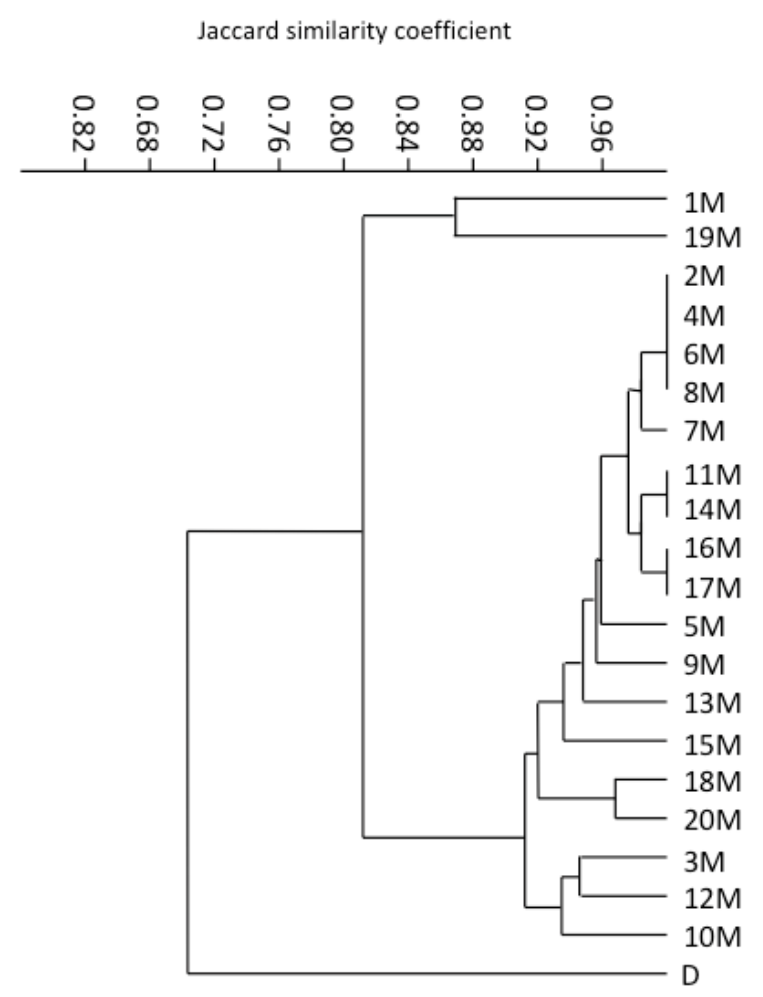

Figure 5. Dendrogram of 20 plants treated with the chemical mutagen EMS, evaluated by RAMP markers, using the nine combinations of primers. D: control.

Hoang et al. [32] showed a GS of 0.98 for mutants for rice seeds obtained by irradiation with gamma rays as a mutagenic agent with respect to the original plant and a percentage of polymorphism of $21.2 \%$ using RAMP markers. They showed that RAMP markers display a higher degree of polymorphism compared to RAPD alone. This is due to the fact that RAMP markers detect not 
only the polymorphisms detected with RAPD primers, but also the polymorphisms associated with microsatellites, and, in any case, a combination of both generate new markers, which may or may not encode genes.

Falk et al. [38] reported obtaining a mutant of lavender plants with increased amounts of sesquiterpenes and monoterpenes through the application of EMS. Chemical mutagenesis could be used as an alternative to obtain genotypes with variations in the yield or composition of the essential oil.

\section{Conclusions}

The in vitro cultivation of Mexican oregano was established via axillary buds of three different genotypes and three of its sub-cultivations in MS medium supplemented with $0.5 \mathrm{mg} \mathrm{L}^{-1}$ of BA.

Nodal segments treated with EMS showed a decrease in the number of shoots and in their size when the concentration of the mutagen was increased. The greater number of shoots was obtained with $1-2 \mathrm{~h}$ of exposure to $0.1 \%$ EMS.

Regarding the evaluation of genetic variability, RAMP markers allowed the evaluation of the genetic fidelity of the propagation method via axillary buds for the three genotypes and for the successive stages of cultivation. It is worth mentioning that the use of EMS allowed to increase genetic variability at rates similar to those found in wild populations, obtaining a percentage of polymorphism of 34 and $35 \%$, respectively, and thus has a potential use or obtaining new varieties.

Author Contributions: L.A.M.-M. and O.A.C.-H., carried out the design of the study and wrote this paper. L.A.M.-M., O.A.C.-H., A.R.-S., and G.J.A.H., conducted the plant cultivation, molecular analysis, and statistical analysis of this work. V.O.C.-M., participated in experiment management. M.I.T.-M., R.L.-I., and R.C.A., reviewed and edited this research paper.

Funding: This research received no external funding.

Acknowledgments: The authors wish to thank the following students: Martínez Rojo N. F., Marrón Chavéz I., Pedroza C., for their experimental assistance.

Conflicts of Interest: The authors declare no conflict of interest.

\section{References}

1. Alamgir, A.N.M. Pharmacognostical Botany: Classification of medicinal and aromatic plants (MAPs), botanical taxonomy, morphology, and anatomy of drug plants. In Therapeutic Use of Medicinal Plants and Their Extract: 1. Progress in Drug Research; Springer: Cham, Switzerland, 2017; Volume 73, pp. 177-293. ISBN 978-3-319-6386-1.

2. Villavicencio-Gutiérrez, E.; Cano-Pineda, A.; Garcia-Cuevas, X. Metodología para determinar las existencias de orégano (Lippia graveolens H.B.K.) en rodales naturales de parras de la fuente Coahuila; Instituto Nacional de Investigaciones Agrícolas y Pecuarias, Ed.; Instituto Nacional de Investigaciones Agrícolas y Pecuarias: Saltillo, Mexico, 2010; p. 42. ISBN 978-607-425-295-8.

3. Güereca, M.C.G.; Hernandez, M.S.; Kite, G.; Vazquez, M.M. Antioxidant activity of flavonoids from the stem of the Mexican oregano (Lippia graveolens HBK var. berlandiefi Schauer). Rev. Fitotec. Mex. 2007, 30, 43-49.

4. Muñoz-Acevedo, A.; Torres, E.A.; Gutierrez, R.G.; Cortes, S.B.; Cervantes-Diaz, M.; Tafurt-Garcia, G. Some Latin American plants promising for the cosmetic, perfume and flavor industries. In Therapeutic Medicinal Plants: From Lab to the Market; Duarte, M.C.T., Rai, M., Eds.; CRC Press: Boca Raton, FL, USA, 2016; Volume 1, pp. 279-330. [CrossRef]

5. Bueno-Durán, A.Y.; Cervantes-Martínez, J.; Obledo-Vázquez, E.N. Composition of essential oil from Lippia graveolens: Relationship between spectral light quality and thymol and carvacrol content. J. Essent Oil Res. 2014, 3, 153-160. [CrossRef]

6. González-Trujano, M.E.; Hernández-Sánchez, L.Y.; Muñoz-Ocotero, V.; Dorazco-González, A.; Guevara-Fefer, P.; Aguirre-Hernández, E. Pharmacological evaluation of the anxiolytic-like effects of Lippia graveolens and bioactive compounds. Pharm. Biol. 2017, 55, 1569-1576. [CrossRef]

7. Hernández-Hernández, E.; Regalado-González, C.; Vázquez-Landaverde, P.; Guerrero-Legarreta, I.; García-Almendárez, B.E. Microencapsulation, Chemical Characterization, and Antimicrobial Activity of 
Mexican (Lippia graveolens H.B.K.) and European (Origanum vulgare L.) Oregano Essential Oils. Sci. World J. 2014, 12. [CrossRef]

8. Avila-Sosa, R.; Gastélum-Franco, M.G.; Camacho-Dávila, A.; Torres-Muños, J.V.; Nevárez-Moorillón, G. Extracts of Mexican Oregano (Lippia berlandieri Schauer) with Antioxidant and Antimicrobial Activity. Food Bioprocess Technol. 2010, 3, 434-440. [CrossRef]

9. Martínez-Rocha, A.; Puga, R.; Hernández-Sandoval, L.; Loarca-Piña, G.; Mendoza, S. Antioxidant and Antimutagenic Activities of Mexican Oregano (Lippia graveolens Kunth). Plant. Foods Hum. Nutr. 2008, 63, 1-5. [CrossRef] [PubMed]

10. Rodriguez-Garcia, I.; Cruz-Valenzuela, M.R.; Silva-Espinoza, B.A.; Gonzalez-Aguilar, G.; Moctezuma, E.; Gutierrez-Pacheco, M.; Tapia-Rodriguez, M.; Ortega-Ramirez, L.; Ayala-Zavala, J.F. Oregano (Lippia graveolens) essential oil added within pectin edible coatings prevents fungal decay and increases the antioxidant capacity of treated tomatoes. J. Sci. Food Agric. 2016, 96, 3772-3778. [CrossRef] [PubMed]

11. Calpouzos, L. Botanical aspects of Oregano. Econ. Bot. 1954, 8, 222-233. [CrossRef]

12. Ocampo-Velázquez, R.V.; Malda-Barrera, G.X.; Suárez-Ramos, G. Reproductive biology of Mexican oregano (Lippia graveolens Kunth) in three exploitation conditions. Agrociencia 2009, 43, 475-482.

13. Costa, A.S.; Arrigoni-Blank, M.F.; Blank, A.F.; Mendonza, A.B.; Amancio, V.F.; Ledo, A.S. Estabelecimento de alecrim-pimenta in vitro. Hortic. Bras. 2007, 25, 068-072. [CrossRef]

14. Castellanos-Hernández, O.A.; Acevedo-Hernández, G.J.; Torres-Morán, M.I.; Zurita, F.; Gutiérrez-Lomelí, M.; Del Toro-Sánchez, C.L.; Rodríguez-Sahagún, A. In vitro Clonal Propagation and Regeneration of the Commercially Important Plant Mexican Oregano (Lippia graveolens). In Vitro Cell. Dev. Biol. Plant 2013, 49, 620-625. [CrossRef]

15. Ahloowalia, B.; Maluszynski, M. Induced mutations-A new paradigm in plant breeding. Euphytica 2001, 118, 167-173. [CrossRef]

16. Yolmeh, M.; Khomeiri, M. Effect of mutagenesis treatment on antimicrobial and antioxidant activities of pigments extracted from Rhodotorula glutinis. Biocatal. Agric. Biotechnol. 2017, 10, 285-290. [CrossRef]

17. Bahl, J.R.; Sinha, S.; Naqvi, A.A.; Bansal, R.P.; Gupta, A.K.; Kumar, S. Linalool-rich essential oil quality variants obtained from irradiated stem nodes in Lippia alba. Flavour Fragr. J. 2002, 17, 127-132. [CrossRef]

18. Khalil, F.; Naiyan, X.; Tayyab, M.; Pinghua, C. Screening of EMS-Induced Drought-Tolerant Sugarcane Mutants Employing Physiological, Molecular and Enzymatic Approaches. Agronomy 2018, 8, 226. [CrossRef]

19. Srivastava, D.; Gayatri, M.C.; Sarangi, S.K. In vitro mutagenesis and characterization of mutants through morphological and genetic analysis in orchid Aerides crispa Lindl. Indian J. Exp. Biol. 2018, 56, 385-394.

20. Murashige, T.; Skoog, F. A revised medium for rapid growth and bioassays with tobacco tissue culture. Physiol. Plant. 1962, 15, 473-497. [CrossRef]

21. Zhang, D.X.; Hewitt, G.M. Special DNA Extraction Methods for Some Animal Species. In Molecular Tools for Screening Biodiversity: Plants and Animals; Karp, A., Isaac, P.G., Ingram, D.S., Eds.; Chapman and Hall: London, UK, 1998; pp. 25-31. ISBN 9789400900196.

22. Pu, Z.E.; Hou, Y.C.; Xu, X.X.; Yan, Z.H.; Wei, Y.M.; Lan, X.J.; Zheng, Y.L. Genetic Diversity Among Barley Populations from West China Based on RAMP and RAPD Markers. Asian J. Plant. Sci. 2009, 8, 111-119. [CrossRef]

23. Rohlf, F.J. NTSYS-pc Numerical Taxonomy and Multivariate Analysis System, version 2.00; Exeter Software Publications: Setauket, NY, USA, 1997; p. 31. Available online: http:/ /www.exetersoftware.com/cat/ ntsyspc/ntsyspc.html (accessed on 12 December 2018).

24. Hammer, Ø.; Harper, D.A.T.; Ryan, P.D. PAST: Paleontological statistics software package for education and data analysis. Palaeontol. Electron. 2001, 4, 1-9.

25. Cao, H.; Yang, J.; Peng, Z.S.; Kang, C.Y.; Chen, D.C.; Gong, Z.C.; Tan, X. Micropropagation of Penthorum chinense Through Axillary Bud. In Vitro Cell. Dev. Biol. Plant 2007, 43, 149-153. [CrossRef]

26. Islam, M.R.; Khan, R.; Hossain, S.N.; Ahmed, G.; Hakim, L. In vitro Clonal Propagation of Vitex negundo L. An important Medicinal Plant. Plant Tissue Cult. Biotechnol. 2009, 19, 113-117. [CrossRef]

27. Zucchi, M.I.; Arizono, H.; Morais, V.A.; Pelegrinelli, M.H.; Carneiro, M.L. Genetic instability of sugarcane plants derived from meristem cultures. Genet. Mol. Biol. 2002, 25, 91-96. [CrossRef]

28. Chaturvedi, R.; Razdan, M.K.; Bhojwani, S.S. In vitro clonal propagation of an adult tree of neem (Azadirachta indica A. Juss.) by forced axillary branching. Plant Sci. 2004, 166, 501-506. [CrossRef] 
29. Junaid, A.; Mujib, A.; Sharma, M.P. Effect of growth regulators and ethyl methane sulphonate on growth, and chlorophyll, sugar and proline contents in Dracaena sanderiana cultured in vitro. Biol. Plant. 2008, 52, 569-572. [CrossRef]

30. Chikelu, M.; Rownak, A.; Souleymane, B.; Shri-Mohan, J. Induced mutagenesis in plants using physical and chemical agents. In Plant Cell Culture: Essential Methods; Davey, M.R., Anthony, P., Eds.; John Wiley \& Son, Ltd.: Hoboken, NJ, USA, 2010; pp. 111-127. ISBN 9780470686515.

31. Glandorf, B.; de Loose, M.; Davies, H. Evaluation of changes in the genome of plants through application of new plant breeding techniques. Annex 15. In New Plant Breeding Techniques. State-of-the-Art and Prospects for Commercial Development; Lusser, M., Parisi, C., Plan, D., Rodríguez-Cerezo, E., Eds.; EUR 24760 EN; European Commission, Joint Research Centre: Brussels, Belgium, 2011; pp. 141-155.

32. Hoang, T.M.L.; De Filippis, L.F.; Le, X.T. Salt Tolerance and Screening for Genetic Changes in Rice Mutants After Gamma Irradiation using RAPD and Microsatellite (RAMP) markers. Open Hortic. J. 2009, 2, 62-69. [CrossRef]

33. Xi, M.; Sun, L.; Qiu, S.; Liu, J.; Xu, J.; Shi, J. In vitro Mutagenesis and Identification of Mutants via ISSR in Lily (Lilium longiflorum). Plant Cell Rep. 2012, 31, 1043-1051. [CrossRef]

34. Martins, M.; Sarmento, D.; Oliveira, M.M. Genetic stability of micropropagated almond plantlets, as Assessed by RAPD and ISSR Markers. Plant Cell Rep. 2004, 23, 492-496. [CrossRef]

35. Chittora, M. Assessment of genetic fidelity of long term micropropagated shoot cultures of Achras sapota L. var. 'Cricket Ball' as assessed by RAPD and ISSR markers. Indian J. Biotechnol. 2018, 17, 492-497.

36. Rathore, M.S.; Yadav, P.; Mastan, S.G.; Prakash, C.R.; Singh, A.; Agarwal, P.K. Evaluation of Genetic Homogeneity in Tissue Culture Regenerates of Jatropha curcas L. Using Flow Cytometer and DNA-based Molecular Markers. Appl. Biochem. Biotechnol. 2014, 172, 298-310. [CrossRef] [PubMed]

37. Zhao, L.; Li, M.; Guangze, C.; Pan, T.; Shan, C. Assessment of the Genetic Diversity and Genetic Relationships of Pomegranate (Punicagranatum L.) in China Using RAMP Markers. Sci. Hortic. 2013, 151, 63-67. [CrossRef]

38. Falk, L.; Biswas, K.; Boeckelmann, A.; Lane, A.; Mahmoud, S.S. An Efficient Method for Micropropagation of Lavenders: Regeneration of a Unique Mutant. J. Essent Oil Res. 2009, 21, 225-228. [CrossRef]

(C) 2019 by the authors. Licensee MDPI, Basel, Switzerland. This article is an open access article distributed under the terms and conditions of the Creative Commons Attribution (CC BY) license (http:/ / creativecommons.org/licenses/by/4.0/). 